Николай Соколов, Лилия Рехтина

\title{
ОТ МОЛОДЕЖНОЙ МИГРАЦИИ К МИГРАЦИИ ПОЖИЛЫХ: ПАРАДОКСЫ СТАРЕНИЯ ПРИНИМАЮЩЕГО ОБЩЕСТВА
}

Статья посвящена анализу структурно-возрастных изменений миграции, которые происходят на фоне увеличения миграционных потоков, с одной стороны, и процесса старения населения, с другой. Миграция, как массовый процесс, повторяет явление «перевернутой пирамиды», порождая феномен, названный нами «миграция пожилых». Старение миграции проявляется на фоне трансформации миграции молодежной - это взаимосвязанные и взаимодополняющие друг друга процессы. Методологически анализ лежит на стыке теорий, рассматривающих феномен массовой миграции и социологических концепций, описывающих процесс старения населения - в первую очередь исследующих «третий возраст» как относительно новую группу населения, требующую к себе особого отношения и подхода. Эмпирической базой исследования служат данные опроса, проведенного осенью 2016 г. в Санкт-Петербурге. В ходе опроса собраны данные о возрастной, гендерной, географической и профессиональной структуре приезжего населения города. Основная часть анализа выполнена для целевой категории мигрантов, переехавших жить в СанктПетербург в возрасте старше 40 лет в период 1995-2016 гг. Данные исследования свидетельствуют о «старении» и «взрослении» миграции. При этом характер «пожилой» миграции радикально отличается от сложившихся стереотипов о «молодежной» миграции - ведущую роль в ней играют социальные и родственные сети, на которые ориентированы пожилые приезжие. Наблюдаемые тенденции старения миграции позволяют прогнозировать усложнение процессов адаптации и интеграции, вплоть до полной неэффективности традиционных механизмов взаимодействия агентов принимающего сообщества с пожилыми мигрантами. Последних нельзя рассматривать в роли дешевого и легко доступного

Николай Викторович Соколов - к.с.н., доцент, Санкт-Петербургский государственный университет, Санкт-Петербург, Россия. Электронная почта: nvsspb@yandex.ru

Лилия Сергеевна Рехтина - социолог, Санкт-Петербургский государственный университет, Санкт-Петербург, Россия. Электронная почта: lisabet-09@mail.ru 
источника, пополняющего производительные силы принимающей стороны - они прибывают с целью обмена ресурсами. Старение миграции включает механизмы социальной трансформации, которая играет роль мощного креативного источника для принимающего социума, но в то же время является источником серьезных рисков в связи с радикальным снижением возможностей управления миграцией.

Ключевые слова: миграция, социология миграции, «третий» возраст, старение, социальные и родственные сети, пожилые мигранты

DOI: 10.17323/727-0634-2018-16-1-51-66

Сложившиеся теоретические взгляды на социальную и географическую мобильность приписывают миграционную активность молодежи, однако за сто лет, прошедших с момента появления теории социальной мобильности, в обществе произошли трансформации, предопределяющие увеличение доли населения, мигрирующего в пожилом возрасте. Прежде всего, это глобальный феномен «перевернутой пирамиды»: доля молодежи в составе населения уменьшается и один из очевидных результатов - старение всех массовых социальных процессов.

Старение населения ассоциируется с миграцией, но пока только в контексте восполнения демографических потерь принимающими обществами. Например, по некоторым расчетам странам Европы только для поддержания существующей пропорции населения надо к 2050 г. принять 169 млн мигрантов, а для замещения потерь от естественной убыли до 1,5 млрд (Бьюкенен 2003: 40). В течение десятилетий «перевернутая пирамида» рассматривалась как угроза экономическому благополучию, стареющие жители - как новые иждивенцы, а мигранты - как «альтернативная» молодежь. Однако наблюдение реальных миграционных тенденций показывает, что в результате к «своим» иждивенцам (старикам) добавляются «пришлые» - пожилые мигранты, трудовой потенциал которых невелик (Веселов и др. 2015: 110). Так восполняет ли миграция естественную убыль, или она стареет как и все вокруг?

Ответ требует совмещения теоретических подходов в исследовании массовых миграций и современных социологических концепций старения, что и определило методологическую стратегию. Среди классических исследований, посвященных социологии миграции, отдельного упоминания в контексте данной работы заслуживает, пожалуй, только концепция маргинальной личности (Park 1928), объясняющая формирование устойчивых социальных дистанций между мигрантом и принимающим сообществом. Маргинальность, понимаемая Робертом Парком как раздвоенность социального бытия, как конфликт установок отправляющего и принимающего сообществ, более выражена у пожилых мигрантов и переживается ими острее. Возможно, именно угроза оказаться в маргинальной ситуации 
до недавнего времени блокировала массовую миграцию пожилых, социальный статус которых воспринимался как несовместимый с рискованными стратегиями.

Однако текущие социально-демографические трансформации открывают двери для пожилых мигрантов. Старение связанно не только с увеличением продолжительности жизни, но с повышением ее качества. Слово «старик» все чаще не тождественно «иждивенцу», а старость - состоянию социального или физического инвалида (Ильницкий и др. 2017). В развитых странах старость напрямую не связанна с социальной стигматизацией, бедностью, социальной дезадаптацией (Григорьева, Келасьев 2017), хотя реальное положение российских стариков сегодня выглядит именно так (Щукина 2008). Следовательно, если раньше пожилые исключались из миграционного процесса, в т.ч. и в контексте их общей эксклюзии, барьеры данного рода в значительной мере разрушены.

Принципиально изменилась ситуация в сфере занятости - в пожилом возрасте люди не просто продолжают трудиться «по инерции», но и профессионально развиваются. И хотя люди «третьего возраста» все еще рассматриваются как нагрузка на общество, отмечается, что «гарантом поддержания темпов экономического роста и благосостояния «стареющих» государств является эффективная реализация ресурсного потенциала старшего поколения» (Барсуков, Чекмарева 2017: 92). С одной стороны, это проявляет противоречие между трудовой миграцией и занятостью пожилых, с другой - предполагает и увеличение трудовой миграции пожилых.

Другой важный момент трансформации старения состоит в том, что раздвигаются возрастные рамки допустимости и пригодности повседневных практик (Григорьева и др. 2015). Сегодня пожилые люди могут продолжать активную жизнь, реализовывать привычные практики, сохраняя накопленный социальный капитал. Но изменения в восприятии старости происходят медленно и дифференцировано - в т.ч. и в сознании самих пожилых, которые по-разному представляют социальные и культурные границы, стигмы и собственные права (Богданова 2016). Например, это отражается на реализации прямо связанных с миграцией прав на образование и самореализацию, труд и независимость (Левинсон 2012).

Конечно, единичные случаи миграции пожилых бывали всегда, но современная статистика уже фиксирует массовое включение людей старшего возраста в миграцию как следствие перевернутой демографической пирамиды. Например, статистически значимое смещение долей миграции в сторону пожилого населения страны отмечено в Китае - в 2016 г. общая численность переселенцев в возрасте старше 60 лет составила 17,8 млн человек (GBTIMES Россия 2016).

Российский контекст феномена миграции пожилых частично изучен в рамках исследований «третьего возраста» - чаще в качестве одного из дополнительных, отягощающих интеграцию в принимающее общество, 
факторов (Суслова 2015; Неваева 2014; Есилов, Калашникова 2015). Статистически значимый пик внутрироссийской миграции в возрасте от 50 до 65 лет из северных регионов России описали Лилия Карачурина и Никита Мкртчян (Карачурина, Мкртчян 2016). В другом исследовании обращается внимание на появление регионов концентрации пожилого населения, в результате чего формируется миграционно-возрастная дифференциация пространства России (Владимиров 2005). Рассматривая миграцию пожилых Алтайского края, Елена Тарасова отмечает ее ориентацию на территории проживания родственников (детей, внуков) и семейный характер (Тарасова 2013). Об увеличении миграционного притока пожилых мигрантов и качественно ином характере миграции этой категории населения в Самарской области пишут Геннадий Гридасов с коллегами (Гридасов и др. 2011). Упомянутые исследования показывают, что миграция пожилых актуальна для российского общества и наблюдается эмпирически.

Целью представленного в настоящей статье исследования является описание тенденций старения входящей миграции в Санкт-Петербурге и особенностей контингента пожилых приезжих. Ниже представлены концептуальная модель и гипотеза исследования, описаны методы и результаты массового опроса в Санкт-Петербурге, в ходе которого была обследована подвыборка пожилых приезжих.

\section{Концептуальная модель и гипотеза}

Массовое включение пожилых в миграцию в современном обществе ведет не просто к увеличению доли старших возрастных групп в структуре перемещающегося населения, а принимает характер нового социального явления, условно обозначаемого здесь как «пожилая» ${ }^{1}$ миграция и отличающегося следующими особенностями, которые представляют авторскую модель исследования.

Мотивация. Ведущую роль в мотивировании пожилых к переезду играют две группы факторов - во-первых, трудности самостоятельной жизни, без поддержки близких; во-вторых, деградирует, разрушается привычная социальная среда, в которой человек функционировал значительную часть жизни и к которой был адаптирован.

Рекрутирование. «Пожилая» миграция в значительной мере является вынужденной и реализуется, прежде всего, посредством механизма воссоединения с родней. Это предполагает реставрацию родственных и социальных сетей и решает задачу не только ухода за немощными, но и профилактики этой немощи и эксклюзии путем включения пожилых в функционирование

\footnotetext{
${ }^{1}$ Рассматриваемое явление касается массового включения в миграцию возрастных категорий, ранее практически исключенных из нее. Поэтому в данном контексте «старение» миграции могут представлять и возрастные когорты, традиционно не относящиеся к пожилым.
} 
домохозяйств. Другой важный механизм - вытеснение пожилых из «насиженных мест», связанное с разрушением привычной повседневной среды, происходящее как в явной (программы переселения, репатриации), так и латентной (деградация и давление среды) формах.

Задачи переезда. Специфической задачей пожилого переселенца является трансфер материальных, социальных и культурных ресурсов, накопленных в течение жизни, с целью их последующей конвертации в ликвидные в принимающем сообществе активы. Это предполагает минимизацию рисков и потерь, что прямо противоположно рискованному характеру миграции.

Адаптация и интеграция. Пожилые переселенцы ориентированы, прежде всего, не на принимающий социум, а на свою социальную сеть, реинтеграция в которую является для них ключевой задачей. В результате адаптационные процессы происходят в триаде «принимающий социум - адаптированные мигранты - вновь прибывшие пожилые мигранты» и усложняются.

Географическая дистанция усиливает депривацию и стимулирует воссоединение, однако делает переезд сложнее, дороже и рискованнее. Миграция на относительно небольшие расстояния может быть растянута во времени, включать в себя пробные поездки и допускает возвращение. Культурные дистанции между центром и «глубинкой», благополучными и депрессивными ареалами, этническими и конфессиональными группами складываются в сложную систему рисков и препятствий для адаптации в ее традиционном понимании.

Наша гипотеза заключается в том, что старение миграции означает пересмотр миграционной парадигмы как таковой - вместо высвобождения и перемещения человеческих ресурсов между воображаемыми сообществами (странами, народами, городами и пр.) возникают потоки материальных и культурных ресурсов внутри социальных (прежде всего родственных) сетей, на смену адаптации и интеграции приходит реконструкция социальности.

\section{Методы}

Для проверки исследовательской гипотезы и описания процессов «пожилой» миграции использованы данные опроса, выполненного в СанктПетербурге (2016 г.) с целью определения фактических структурных пропорций населения. Использована методика уличного опроса, выбор которой определялся необходимостью обеспечить представительство мигрантов в общегородской выборке. Выборка кластерная с шаговым (систематическим) отбором внутри кластеров, охватывает основные территориальные сегменты города.

Всего было опрошено 821 человек. Максимальная статистическая погрешность (ошибка выборки) для одномерных распределений составляет $\Delta=3,5 \%$ для доверительной вероятности 95,4\%. С целью контроля репре- 
зентативности в ходе опроса фиксировались ориентировочные половозрастные параметры каждого отобранного с установленным шагом, но отказавшегося от интервью прохожего. На основании собранных данных выполнена процедура ремонта выборки с использованием весовых коэффициентов, рассчитанных для основных половозрастных категорий генеральной совокупности «взрослое (16 лет и старше) население СанктПетербурга». Статистическая обработка данных выполнена с помощью программы SPSS.

\section{Результаты}

75 \% опрошенных, не являющихся уроженцами Санкт-Петербурга, переехали жить в город в возрасте не старше 30 лет (Таблица 1). Доля тех, кто совершил такой переезд в возрасте старше 50 лет составляет только 3,3\%, а случаи миграции в возрастной категории «за 60 лет» в обследованной выборке единичны (менее $0,5 \%$ ). Однако в целом приезжие составляют более половины (51,3\%) горожан, а категория пожилых мигрантов в абсолютном выражении оценивается десятками тысяч человек.

Поиск динамической тенденции в возрастной структуре контингента прибывающих в Петербург мигрантов показал, что можно говорить не только о «старении», но и о «взрослении» входящей миграции. В «доперестроечный» период доминировала не просто молодежная, а подростковая и юношеская миграция, которая значительно сократилась в эпоху экономических реформ. Вместо нее на рубеже 1980-1990-х возникает, как массовое явление, «взрослая» миграция, в которой начинают доминировать молодые (до 30 лет) приезжие, их доля устойчиво росла на протяжении всего периода ретроспективного наблюдения. Следующим важным сигналом служит массовое включение в миграцию сорокалетних - в 2010-е гг. эта категория удвоила свое присутствие в составе прибывающих в Санкт-Петербург. Пятидесятилетние присутствуют на миграционной «сцене» Петербурга с середины 1990-х, но в последнее десятилетие их удельный вес не увеличивается. Зато в 2010-х гг. впервые появляются мигранты в возрастной категории «старше 60 лет». Здесь представлены результаты применения упрощенной статистической модели, не учитывающей естественную убыль населения, которая является существенным фактором, определяющим структуру населения города на момент опроса. Тем не менее эта модель в достаточной мере демонстрирует эффект массификации пожилой миграции. Например, в выборке полностью отсутствуют респонденты возрастной категории «60+», приехавшие в СанктПетербург в 1990-е - начале 2000-х. гг., хотя по статистике, существенная их часть должна была дожить до 2016 г.

Для углубленного анализа выбраны две целевые категории мигрантов - совершившие переезд в возрасте от 40-50 и старше 50 лет. Последних 
с той или иной мерой условности можно отнести к пожилым. Сорокалетние же интересны тем, что отражают тенденцию «старения» миграции - их доля в актуальном (2014-2016 гг.) притоке в Санкт-Петербург превышает 1/5 $(22 \%)$. На закате советской эпохи сорокалетних литераторов относили к категории «молодые писатели», потому что к этому возрасту они еще не успевали завершить процесс интеграции в литературное сообщество. Теперь мигранты 40-45 лет, с точки зрения законов миграции, могут рассматриваться как представляющие «пожилую» миграцию.

Возрастная структура контингентов, прибывавших

Таблица 1

в Санкт-Петербург/Ленинград в разные периоды времени (\% опрошенных по категориям мигрантов, выделенным в зависимости от периода прибытия)

\begin{tabular}{|c|c|c|c|c|c|}
\hline \multirow[b]{2}{*}{$\begin{array}{c}\text { Возраст, в котором совершен переезд } \\
\text { в Санкт-Петербург/Ленинград }\end{array}$} & \multicolumn{5}{|c|}{$\begin{array}{c}\text { Период переезда } \\
\text { в Санкт-Петербург/Ленинград }\end{array}$} \\
\hline & 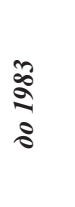 & $\begin{array}{l}\frac{\pi}{2} \\
\frac{1}{2} \\
2\end{array}$ & 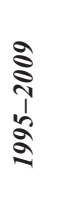 & 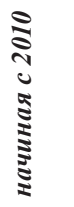 & 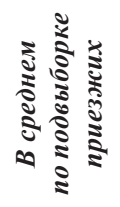 \\
\hline До 11 лет включительно - дети & 13,3 & 16,7 & 7,5 & $0,7^{*}$ & 7,8 \\
\hline $\begin{array}{l}\text { 12-16 лет - подростки, абитуриенты ПТУ, } \\
\text { техникумов и др. }\end{array}$ & 17,3 & 9,5 & 4,7 & 3,6 & 8,2 \\
\hline $\begin{array}{l}\text { 17-20 лет - выпускники средних школ, } \\
\text { студенты }\end{array}$ & 41,8 & 23,8 & 25,5 & 19,6 & 27,2 \\
\hline 21-30 лет - молодежь & 25,5 & 33,3 & 32,1 & 37,7 & 32,3 \\
\hline 31-40лет-тридцатилетние & 2,0 & 14,3 & 17,0 & 14,5 & 12,3 \\
\hline 41-50 лет - сорокалетние & - & 2,4 & 8,5 & 17,4 & 8,8 \\
\hline 51-60 лет - пятидесятилетние & - & - & 4,7 & 5,1 & 2,9 \\
\hline старше 60 лет - пожилые & - & - & - & 1,4 & 0,4 \\
\hline Всего & 100 & 100 & 100 & 100 & 100 \\
\hline
\end{tabular}

* Малая доля данной категории определена возрастными ограничениями выборки - большинство детей, приехавших в Санкт-Петербург в период после 2010 г. в возрасте младше 12 лет к моменту опроса не достигли 16-летия.

Гендерная структура выделенных категорий радикально различается. Сорокалетние - это преимущественно мужчины (53\%), а «50+» - женщины (67\%). При этом все опрошенные, сообщившие о факте переезда в Петербург в возрасте старше 60 лет, женщины. 
$64 \%$ респондентов-мигрантов категории «40+» - уроженцы других регионов России. Однако доля родившихся на территории других стран неуклонно возрастает и в настоящий момент приближается к половине притока «пожилой миграции» (47\%). Все участвовавшие в опросе международные мигранты родились до 1991 г., в странах, входивших в состав СССР (Украина, Азербайджан, Казахстан, Узбекистан, Киргизия и Таджикистан). В европейской части России родились $77 \%$ внутренних мигрантов. Но тенденция увеличения притока пожилых из удаленных регионов Сибири и Дальнего Востока прослеживается явно - если 10-15 лет назад они составляли немногим более 1/10 от общего числа переезжающих в Петербург, то в 2010-е гг. их доля превысила 1/4 (28,6\%). Увеличение притока из удаленных регионов РФ происходит, прежде всего, за счет миграционной активизации поколения сорокалетних $(26,3 \%)$, которая выступает ключевым моментом тенденции «старения» миграционных процессов. Женщины гораздо активнее включаются в такую миграцию каждая третья (31,6\%) внутренняя мигрантка «40+» прибывает в Петербург из Сибири и других удаленных регионов.

Согласно представленной выше концептуальной модели, мотивационная структура целевого контингента выступает одним из ключевых маркеров «старения» миграции. Для определения мотивации к переезду использован многоальтернативный вопрос: «С какой целью Вы, Ваша семья переехали в Петербург?» Анализ позволил выделить пять ведущих мотивов. Чаще всего, характеризуя цели переезда в Санкт-Петербург, респонденты указывали работу (44,7\%). Мужчины заметно чаще едут именно работать (Таблица 2). При этом наблюдается повышение трудовой мотивации пожилых («50+») в 2010-е гг. Второй по значимости мотив - переезд к близким, членам семьи, супругам, родне $(32,1 \%)$. Это преимущественно женский «повод» $(40 \%)$. Все респонденты, приехавшие в возрасте страше 60 лет, переехали именно к близким, воссоединение с которыми выступает единственной целью миграции в данном возрасте. После 2010 г. многократно сократилась доля мигрантов «40+», направлявшихся в Петербург для обучения. Напротив, ценность северной столицы самой по себе стабильна о желании жить именно в Петербурге сообщил каждый шестой приезжий из рассматриваемых целевых категорий. Образование детей как мотив миграции характерен исключительно (в пределах полученной выборки) для сорокалетних женщин, среди которых 1/4 прибывает в связи с поступлением ребенка в петербургское учебное заведение. Суммарная доля упоминаний всех вариантов ответа респондентами составляет $124 \%$, что свидетельствует о преобладании моноцелевой стратегии миграции.

Анализ мотивационных различий между мигрантами «40+», прибывающими из различных регионов, показал полное исключение уроженцев других стран из образовательной миграции в этом возрасте (Таблица 3). Это характеризует фундаментальное различие принимающего и отправляющих 
сообществ. Но преимущественно трудовой характер миграции из бывших союзных республик - тоже миф, т.к. лишь немногим более $1 / 2$ выходцев из этих стран приезжают с трудовыми целями. Международные мигранты «40+» гораздо чаще россиян приезжают в Санкт-Петербург с целью воссоединения с членами семьи и родней. Среди переселенцев-россиян реже всего приезжают к близким выходцы из удаленных регионов. Данное наблюдение маркирует существенное различие механизмов международной и внутренней миграции на значительные расстояния.

Таблийа 2

Мотивационная структура и связи с отправляющим сообществом гендерные, возрастные и межпоколенческие различия респондентов, совершивших переезд в Санкт-Петербург в возрасте старше 40 лет

(\% опрошенных по выделенным категориям мигрантов)

\begin{tabular}{|c|c|c|c|c|c|c|c|}
\hline & \multicolumn{2}{|c|}{ Пол } & \multicolumn{2}{|c|}{$\begin{array}{l}\text { Возраст } \\
\text { переезда, лет }\end{array}$} & \multicolumn{2}{|c|}{$\begin{array}{c}\text { Период } \\
\text { переезда, годыl }\end{array}$} & \multirow{2}{*}{ 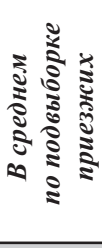 } \\
\hline & 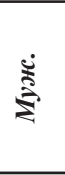 & 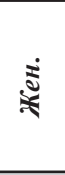 & $\frac{\pi}{7}$ & $\begin{array}{l}0 \\
\Xi \\
5 \\
5 \\
5 \\
\Sigma \\
n \\
n\end{array}$ & 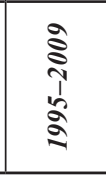 & 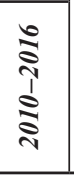 & \\
\hline \multicolumn{8}{|c|}{ С какой целью Вы, Ваша семья переехали в Петербург?* } \\
\hline Работать & 61,9 & 32 & 45,5 & 41,7 & 38,5 & 46,9 & 44,7 \\
\hline Учиться & 4,8 & 16,7 & 12,1 & 15,4 & 30,8 & 6,2 & 12,2 \\
\hline $\begin{array}{l}\text { К близким, } \\
\text { родственникам, супругам }\end{array}$ & 23,8 & 40 & 34,4 & 23,1 & 38,5 & 28,1 & 32,1 \\
\hline Обучение детей & - & 24 & 18,2 & - & 21,4 & 9,4 & 12,4 \\
\hline Хотели жить в северной столице & 19 & 12,5 & 6,2 & 30,8 & 14,3 & 15,6 & 14,6 \\
\hline \multicolumn{8}{|c|}{$\begin{array}{l}\text { Поддерживаете ли Вы связь с родными, друзьями, } \\
\text { оставшимися там, откуда Вы приехали?* }\end{array}$} \\
\hline Никаких связей не осталось & 5,6 & 26,1 & 13,8 & 23,1 & 30 & 12,9 & 16,5 \\
\hline Переписка по почте & 5,6 & 30,4 & 17,9 & 23,1 & 27,3 & 19,4 & 20 \\
\hline Общение по телефону, Интернет & 94,4 & 73,9 & 86,2 & 76.9 & 70 & 87,1 & 80 \\
\hline Поездки на родину & 73,7 & 34,8 & 67,9 & 23,1 & 45,5 & 58,1 & 53,6 \\
\hline Прием гостей с родины & 31,6 & 39,1 & 41,4 & 23,1 & 45,5 & 32,3 & 34,8 \\
\hline $\begin{array}{l}\text { Отправляют деньги, } \\
\text { вещи, подарки }\end{array}$ & 36,8 & 8,7 & 25 & 7,7 & 30 & 16,1 & 20,2 \\
\hline $\begin{array}{l}\text { Получают } \\
\text { финансовую помощь, посылки }\end{array}$ & 5,6 & 13 & 10,3 & 7,7 & - & 12,9 & 9,7 \\
\hline На родине осталась часть семьи & 31,6 & 17,4 & 31 & 7,7 & 20 & 25,8 & 23,7 \\
\hline
\end{tabular}

* В таблице представлены только те варианты ответа, частота упоминания которых позволяет выполнить перекрестный анализ. 
Таблицча 3

Влияние географического фактора на мотивационную структуру и связи с отправляющим сообществом респондентов, совершивших переезд в СанктПетербург в возрасте старше 40 лет (\% опрошенных по выделенным территориальным сегментам)

\begin{tabular}{|c|c|c|c|c|c|c|}
\hline & \multicolumn{6}{|c|}{ Место рожндения } \\
\hline & \multicolumn{3}{|c|}{ Россия } & \multicolumn{3}{|c|}{ За пределами РФ } \\
\hline & $\underset{5}{5}$ & 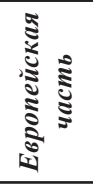 & 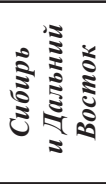 & $\underset{\substack{5 \\
5}}{5}$ & 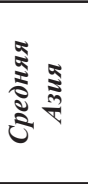 & 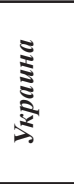 \\
\hline \multicolumn{7}{|c|}{ С какой целью Вы, Ваша семья переехали в Петербург?* } \\
\hline Работать & 40 & 39,1 & 42,9 & 56,2 & 45,5 & 75 \\
\hline Учиться & 20 & 17,4 & 28,6 & - & - & - \\
\hline $\begin{array}{l}\text { К близким, } \\
\text { родственникам, супругам }\end{array}$ & 24,1 & 29,2 & 14,3 & 50 & 36,4 & 75 \\
\hline Обучение детей & 20 & 17,4 & 28,6 & - & - & - \\
\hline Хотели жить в северной столице & 17,2 & 17,4 & 28,6 & 6,2 & 9,1 & - \\
\hline \multicolumn{7}{|c|}{$\begin{array}{l}\text { Поддерживаете ли Вы связь с родными, друзьями, оставшимися там, } \\
\text { откуда Вы приехали?* }\end{array}$} \\
\hline Никаких связей не осталось & 12 & 15 & - & 25 & 36,4 & \\
\hline Переписка по почте & 32 & 26,3 & 42,9 & - & - & - \\
\hline Общение по телефону, Интернет & 88 & 85 & 100 & 75 & 63,6 & 100 \\
\hline Поездки на родину & 46,2 & 45 & 57,1 & 64,7 & 50 & 100 \\
\hline Прием гостей с родины & 48 & 31,6 & 71,4 & 17,6 & 25 & - \\
\hline $\begin{array}{l}\text { Отправляют деньги, вещи, } \\
\text { подарки }\end{array}$ & 16 & 15,8 & 28,6 & 29,4 & 18,2 & 25 \\
\hline $\begin{array}{l}\text { Получают финансовую помощь, } \\
\text { посылки }\end{array}$ & 16 & 10,5 & 28,6 & - & - & - \\
\hline На родине осталась часть семьи & 24 & 31,6 & 28,6 & 18,8 & 9,1 & 25 \\
\hline
\end{tabular}

* В таблице представлены только те варианты ответа, частота упоминания которых позволяет выполнить перекрестный анализ.

Диагностика содержания и интенсивности связей с отправляющим сообществом выполнена при помощи многоальтернативного вопроса: «Поддерживаете ли Вы связь с родными, друзьями, оставшимися там, откуда Вы приехали?». Полная утрата социальных связей встречается редко (16,5 \%). Международные мигранты чаще утрачивают социальный контакт с родиной, например, об этом сообщили $36 \%$ выходцев из среднеазиатских республик (Таблица 3). Отмечена значительная гендерная дифференциация по данному признаку - женщины в пять раз чаще оказываются полностью изолированны от прежних социальных контактов. 
Среди способов взаимодействия с отправляющим сообществом доминирует оперативная коммуникация по телефону и через интернет - в нее включены более $80 \%$ целевой группы. Эпистолярный формат встречается вчетверо реже (20\%), это почти исключительно женская практика, культивирующаяся в сетях, связывающих Петербург с удаленными регионами РФ (Таблица 2). Периодические визиты на родину сильно дифференцированы - мужчины сообщают о таких поездках вдвое чаще, сорокалетние - почти втрое, поколение приехавших после 2010 г.- на 1/3 чаще. Частота упоминания поездок на родину обратно пропорциональна социальной и географической дистанции - 2/3 международных мигрантов и почти $60 \%$ переселенцев из удаленных регионов РФ декларируют такую практику. Прием гостей с родины в среднем практикуется в полтора раза реже $(34,8 \%)$, чем собственные поездки. При этом международные мигранты принимают земляков почти вчетверо реже. А вот для переселенцев из Сибири напротив, является типичным делом. В материальный (в т. ч. денежный) обмен с резидентами отправляющих сообществ включены не более $1 / 3$ целевой группы. Нечастой является и ситуация разрыва семей международных мигрантов. Так, среди приехавших из Средней Азии менее $1 / 10$ части респондентов сообщили, что на родине остался кто-то из членов их семьи.

Чем занимаются в Санкт-Петербурге мигранты категории «40+»? Четверть $(24,8$ \%) на момент опроса находились на пенсии либо не работали. Остальные в равной пропорции распределены между двумя крупными категориями - рабочие, в т.ч. в сфере торговли и услуг $(36,5 \%)$ и специалисты с третичным образованием, предприниматели, руководители всех уровней (38,7\%). При этом персонал, занятый не требующей профессиональной подготовки работой, представлен в целевой группе 10,2\%. Его доля значительно выше среди женщин (20\%) и тех, кто переехал в Петербург после 50-летия (23\%), что иллюстрирует риск маргинализации трудового статуса этих категорий. Деятельность остальных (26,3\%) рабочих предполагает профессиональную подготовку - они составляют почти половину (47\%) всех международных мигрантов, а больше всего их среди выходцев из Средней Азии (63,6\%). Причем в 2010-е гг. удельный вес категории квалифицированных рабочих вырос почти в 5 раз.

Диагностика дискриминации, которой подвергаются пожилые мигранты в принимающем сообществе, важна для характеристики адаптационного и интеграционного процессов. В ходе интервью использован следующий многоальтернативный вопрос: «Вспомните, замечали Вы когда-нибудь разницу в обращении с приезжими по сравнению с обращением местными жителями». Хотя список из 10 вариантов ответа не включал обобщенное отрицательное суждение («ни в чем, никогда не замечал разницы в отношении»), более половины представителей целевой группы ответили именно так (52,6\%). Причем разница между переселенцами- 
россиянами и иностранцами невелика, а вот мужчины в целом и мигранты «нулевых» годов отмечали факты дискриминации существенно чаще.

Чаще всего приезжие замечают различия в отношении к себе на рынке труда (23,7\%). Мужчины указывают на дискриминацию в трудовой сфере втрое (38\%) чаще женщин, сорокалетние - вдвое (28\%) чаще пожилых, а мигранты «нулевых» - вдвое (36\%) чаще по сравнению с теми, кто приехал в 2010-е гг. Второе место в «дискриминационном рейтинге» принадлежит актам публичной коммуникации в различных сферах - на улице, в общественном транспорте, в сфере торговли и обслуживания, при общении с сотрудниками государственных, административных органов (10$14 \%$ ). В данном случае практически отсутствует разница между ответами разных категорий приезжих.

Опрос показал, что миграция в возрасте старше 40 лет не порождает проблем идентификации с петербургским сообществом. Три четверти респондентов из целевой группы в той или иной мере считают себя петербуржцами, причем половина из них (37\%) не испытывает сомнений по этому поводу. Доля носителей петербургской идентичности среди международных мигрантов выше, чем серди переселенцев-россиян и превышает по совокупности трех вариантов ответа 90\%. Переезд в более старшем возрасте ускоряет формирование новой идентичности - среди мигрантов «50+» половина полностью уверена в том, что уже стала петербуржцами, а совокупная доля новых носителей петербургской идентичности превышает $80 \%$.

\section{Выводы}

Исследованием подтверждается тенденция увеличения притока в Санкт-Петербург пожилых мигрантов, как из других регионов РФ, так и из-за рубежа, причем пропорции прибывающих постепенно перераспределяются в пользу международной миграции. Наряду с женщинами пенсионного возраста увеличивается доля мигрантов-мужчин старшего экономически активного возраста. Пожилые мигранты востребованы на рынке труда (3/4 работают), причем подавляющее большинство занято квалифицированным трудом. Для них характерно быстрое формирование петербургской идентичности, что свидетельствует о пространственногеографических основаниях идентификации. Адаптация целевой группы протекает в умеренно благоприятных условиях - менее половины отметили факты дискриминации в различных сферах повседневной жизни.

Важнейшим аспектом «пожилой» миграции является воссоединение с родными и близкими, в большинстве случаев - ранее переехавшими в Санкт-Петербург. Миграция внутри и посредством родственных и социальных сетей в большей мере характерна для международных пожилых переселенцев - половина из них приезжают именно так. Таким образом, миграция пожилых во многих случаях является прямым следствием 
миграции молодежи с определенным временным лагом, что следует учитывать в т.ч. и в рамках стратегического управления миграционными процессами - привлекая молодых, принимающее сообщество «приглашает» к себе их родителей, дедушек и бабушек.

Результаты исследования позволяют предложить вторичную гипотезу о том, что «пожилая» миграция - это завершающая стадия переселения семей, которые и являются базовыми единицами миграционного процесса. И тогда успех миграции определяется не персональной интеграцией приезжего в принимающее сообщество, а завершением переезда семьи, что создает предпосылки для ее нормального воспроизводства на новом месте. В этом случае объектом внимания должны стать семьи российских переселенцев, особенно, как это ни странно - из территориально близких и социально подобных Петербургу местных сообществ, т. к. именно эти условия провоцируют длительный разрыв семьи, затрудняют интеграцию внутренних мигрантов в городское сообщество и консервируют их маргинальность.

\section{Выражение признательности}

Исследование выполнено за счет средств Российского научного фонда, проект № 16-18-10092.

\section{Список источников}

GBTIMES Россия (2016) Необходимость заботы о внуках стала основной причиной миграции пожильх в Китае. Доступно по ссылке: http://ru.gbtimes.com/search/ site/\%2a/author/user\%3a8359 (дата обращения: 1 июля 2017).

Барсуков В.Н, Чекмарева Е.А. (2017) Последствия демографического старения и ресурсный потенциал населения «третьего возраста». Проблемы развития территории, (3): 92-108.

Богданова Е. (2016) Трудовые отношения с участием пенсионеров: забота или манипуляция? Журнал исследований соииальной политики, 14 (4): 535-550.

Бьюкенен П. Дж. (2003) Смерть Запада. М.: АCT.

Веселов Д. С., Сидорова Д. В., Воронина В.В (2015) Исследование положительных и отрицательных эффектов миграции населения для социально-экономического развития стран мира. Вестник Адыгейского государственного университета. Cерия 4: Естественно-математические и технические науки, 1 (154): 105-111.

Владимиров Д. (2005) Направления миграционных передвижений пожилых внутри РФ. В.В. Елизаров, В.Н. Архангельский (ред.) Политика народонаселения: настоящее и будущее. М.: Макс Пресс: 192-195.

Григорьева И.А., Видясова Л.А., Дмитриева А.В., Сергеева О.В. (2015) Пожилье в современной России: между занятостью, образованием и здоровьем. СПб.: Алетейя. 
Григорьева И.А., Келасьев В.Н. (2017) Архаические стереотипы и новые сценарии понимания старения. Успехи геронтологии, 30 (2): 243-247.

Гридасов Г.Н., Захарова Н. О., Балуева Е.С. (2011) Сравнительный анализ динамики миграционного прироста пожилого населения Самарской области. Успехи геронтологии, 4 (4): 707-712.

Есилов А.Б., Калашникова Н.П. (2015) Технологии социальной работы с пожилыми мигрантами: международный опыт и Казахстанская практика. Успехи Геронтологии, 28 (2): 360-365.

Ильницкий А., Колпина Л., Прощаев К. (2017) Пожилой не значит больной: проблемы эйджизма в медицине и здравоохранении. Медицинская газета, (38): 7.

Карачурина Л., Мкртчян Н. (2016) Межрегиональная миграция в России: возрастные особенности. Демографическое обозрение, 3 (4): 47-65.

Левинсон А. (2012) Институциональные рамки старости. Доступно по ссылке: http:/ www.demoscope.ru/weekly/2012/0499/tema07.php (дата обращения: 29 июня 2017).

Неваева Д.А. (2014) Социальная адаптация мигрантов пожилого возраста (по результатам социологического опроса в Алтайском крае). С.Г. Максимова (ред.) Сoциальная интеграция и развитие этнокультур в Евразийском пространстве. Барнаул: Алтайский государственный университет: 128-131.

Суслова Т.Ф. (2015) Адаптация пожилых мигрантов к условиям принимающей страны. Л.Ф. Обухова, И. В. Шаповаленко, М.А. Одинцова (ред.) Горизонты зрелости. М.: ГБОУ ВПО МГППУ: 590-593.

Тарасова Е. В. (2013) Особенности миграции населения старше трудоспособного возраста в Алтайском крае. С.Г. Максимова (ред.) Социальная интеграция и развитие этнокультур в Евразийском пространстве. Барнаул: Алтайский государственный университет: 150-153.

Щукина Н.П. (2008) Социальная политика трансформирующегося российского общества в преломлении социальных практик ее участников. Журнал исследований сочиильной политики, 6 (3): 295-318.

Park R. E. (1928) Human Migration and the Marginal Man. American Journal of Sociology, 33 (6): 881-893. 
Nikolay Sokolov, Liliya Rekhtina

\section{FROM YOUTH MIGRATION TO THE MIGRATION OF THE ELDERLY: THE PARADOXES OF HOST SOCIETY AGING}

The article assesses structural-age changes in the phenomenon of migration. Migration as a mass process is now increasingly subject to the consequences of population ageing, leading to a process that can be called 'migration of the elderly'. Paradoxically, the discovery of this phenomenon was an additional result of the study into the social risks of youth migration. Interestingly, the aging of migration manifests itself precisely against the backdrop of youth migration transformation. Thus, we have found them to be interrelated and mutually complementary processes. The methodology of this research lies at the intersection of theories exploring the phenomenon of mass migration and sociological concepts that describe the aging of the population, primarily those studying the 'third age'. The empirical basis of the study is formed by street polls conducted in St. Petersburg in 2016. The surveys collected data on the age, gender, geographical and occupational structure of migrants. The analysis focused on a target group of migrants who moved to St. Petersburg over the age of forty, in the period 1995-2016. These studies reveal the 'aging' and 'growing up' of migration processes. The nature of 'senior' migration differs from the stereotypes about 'youth' migration. Social and family ties play a leading role here, as elderly migrants are oriented towards them. The observed trends of migration aging allow us to predict a significant complication of adaptation and integration. This can lead to inefficiency in the traditional mechanisms behind the interaction of the host community and senior migrants. Older migrants are not viewed as a cheap labour by the host country, as this category of migrants requires special treatment and approach. Senior migration includes mechanisms of social reconstruction, which captures the host society from the inside, acting as a powerful creative source. It is also a source of serious risks: this could lead to the radical impairment of migration management on the part of the constituent entities of the host community.

Key words: migration, sociology of migration, 'third' age, aging, social and related networks, senior migrants

DOI: 10.17323/727-0634-2018-16-1-51-66

\section{Reference}

Barsukov V., Chekmareva E. (2017) Posledstviya demograficheskogo stareniya i resursnyj potencial naseleniya 'tret'ego vozrasta' [The Consequences of Demographic Ageing and the Resource Potential of the Population of the 'Third' Age]. Problemy razvitiya territorii [Problems of Territory Development], (3): 92-108.

Bogdanova E. (2016) Trudovye otnosheniya s uchastiempensionerov: zabota ili manipulyaciya? [Labour Relations between Employers and Working Pensioners: Care or Manipulation?]. Zhurnal issledovanii social'noj politiki [The Journal of Social Policy Studies], 14 (4): 535-550.

Nikolay V. Sokolov - PhD in Sociology, Associate Professor, St. Petersburg State University, St. Petersburg, Russian Federation. Email: nvsspb@yandex.ru

Liliya S. Rekhtina -Sociologist, St. Petersburg State University, St. Petersburg, Russian Federation. Email:_lisabet-09@mail.ru 
Buchanan P. (2003) Smert' Zapada [The Death of the West]. Moscow: AST.

Esilov A. B., Kalashnikova N.P. (2015) Tekhnologii social'noj raboty s pozhilymi migrantami: mezhdunarodnyj opyt i kazahstanskaya praktika [Technology of Social Work with Elderly Migrants: International Experience and Kazakhstan Practice]. Uspekhi gerontologii [Advances in Gerontology], 28 (2):360-365.

GBTIMES Rossiya (2016) Neobhodimost' zaboty o vnukah stala osnovnoj prichinoj migracii pozhilyh $v$ Kitae [The Need for Caring for Grandchildren was the Main Reason for the Migration of the Elderly in China]. Available at: http://ru.gbtimes.com/search/site/\%2a/author/user\%3a8359 (accessed 01 July 2017).

Gridasov G., Zaharova N., Balueva E. (2011) Sravnitel'nyj analiz dinamiki migracionnogo prirosta pozhilogo naseleniya Samarskoj oblasti [A Comparative Analysis of the Migration Increase Dynamics of the Elderly Population Living in the Samara Region]. Uspekhi gerontologii [Advances in Gerontology], 24 (4): 707-712.

Grigorieva I., Vidyasova L., Dmitrieva A., Sergeeva O. (2015) Pozhilye v sovremennoj Rossii: mezhdu zanyatost'yu, obrazovaniem i zdorov'em [The Elderly in Modern Russia: Between Employment, Education and Health]. St. Petersburg: Aleteya.

Grigor'eva I.A., Kelas'ev V.N. (2017) Arhaicheskie stereotypy i novye scenarii ponimaniya stareniya [Archaic Stereotypes and Modern Approaches for Understanding Aging]. Uspekhi gerontologii [Advances in Gerontology], 30 (2):243-247.

Il'nickij A., Kolpina L., Proshchaev K. (2017) Pozhiloj ne znachitbol'noj: problemy ehjdzhizma v medicine i izdravoohranenii [Elderly does not Mean a Patient: The Problems of Ageism in Medicine and Health Care]. Medicinskaya gazeta [Medical Newspaper], (38): 7.

Karachurina L., Mkrtchyan N. (2016) Mezhregional'nayamigraciya v Rossii: vozrastnye osobennosti [Interregional Migration in Russia: Age Characteristics]. Demograficheskoe obozrenie [Demographic Review], 3 (4): 47-65.

Levinson A. (2012) Institucional'nye ramki starosti [The Institutional Framework of Old Age]. Available at: http://www.demoscope.ru/weekly/2012/0499/tema07.php (accessed 29 June 2017).

Nevaeva D. (2014) Social'naya adaptaciya migrantov pozhilogo vozrasta (po rezul'tatam sociologicheskogo oprosa v Altajskom krae) [Social Adaptation of Older Migrants (Based on the Results of a Sociological Survey in the Altai Territory)]. Social'naya integraciya i razvitie ehtnokul'tur $v$ Evrazijskom prostranstve [Social Integration and Development of Ethno-cultures in the Eurasian Space]. Barnaul: 128-131.

Park R. (1928) Human Migration and the Marginal Man. American Journal of Sociology, 33 (6): 881-893.

Shchukina N. (2008) Social'naya politika transformiruyushchegosya rossijskogo obshchestva v prelomlenii social'nyh praktik ee uchastnikov [The Social Policy of the Transforming Russian Society in the Reforming of Social Practices of its Participants]. Zhurnal issledovanij social'noj politiki [The Journal of Social Policy Studies], 6 (3): 295-318.

Suslova T. (2015) Adaptaciya pozhilyh migrantov k usloviyam prinimayushchej strany [Adaptation of Elderly Migrants to the Conditions of the Host Country]. Gorizonty zrelosti [Levels of Maturity]. Moscow: 590-593.

Tarasova E. (2013) Osobennosti migracii naseleniya starshe trudosposobnogo vozrasta v Altajskom krae [Peculiarities of Migration of the Population over Working Age in the Altai Territory]. Social'naya integraciya i razvitie ehtnokul'tur v Evrazijskom prostranstve [Social Integration and Development of Ethno-cultures in the Eurasian Space]. Barnaul: 150-153.

Veselov D. S., Sidorova D. V., Voronina V.V (2015) Issledovanie polozhitel'nyh i otricatel'nyh effektov migracii naseleniya dlya social'no-ehkonomicheskogo razvitiya stran mira [The Study of Positive and Negative Effects of Migration of the Population for the Social-Economic Development of the Countries of the World]. Vestnik Adygejskogo gosudarstvennogo universiteta. Seriya 4: Estestvenno-matematicheskie i tekhnicheskie nauki [The Bulletin of Adyghe State University: Series 4: Natural and Mathematical and Technical Sciences], 1 (154): 105-111.

Vladimirov D. (2005) Napravleniya migracionnyh peredvizhenij pozhilyh vnutri RF [The Directions of Migratory Movements of the Elderly within the Russian Federation]. V. Elizarov, V. Arhangel'skij (eds.) Politika narodonaseleniya: nastoyashchee i budushchee [Population policy: the present and the future]. Moscow: MaksPress: 192-195. 